\title{
Efeito de doses de silício na resistência do feijoeiro a Spodoptera frugiperda
}

\section{João Hermes Vilela Rodrigues ${ }^{1}$, Marina Robles Angelini' ${ }^{1}$, Reinaldo Silva de Oliveira ${ }^{1}$, Angélica Araújo Queiroz ${ }^{1}$}

${ }^{1}$ Instituto Federal do Triângulo Mineiro, Câmpus de Uberlândia, Minas Gerais. Brasil. E-mail: joaohermes10@ hotmail.com, marinaangelini@iftm.edu.br, reinaldo@iftm.edu.br, angelica@iftm.edu.br

Recebido: 01/03/2018; Aceito: 27/09/2018.

\section{RESUMO}

O presente trabalho objetivou verificar os efeitos das diferentes doses de silício na resistência do feijoeiro à Spodoptera frugiperda. O delineamento adotado foi inteiramente casualizado com quatro tratamentos e cinco repetições. Os tratamentos foram representados pelos níveis de silício: $0 \mathrm{~kg} \mathrm{ha}^{-1} ; 50 \mathrm{~kg} \mathrm{ha}^{-1} ; 100 \mathrm{~kg} \mathrm{ha}^{-1} \mathrm{e} 200 \mathrm{~kg}$ $\mathrm{ha}^{-1}$, sendo o silicato de potássio aplicado ao solo com a adubação de plantio. Avaliou-se o desenvolvimento larval, o período pupal, a biomassa de pupas e a não preferência alimentar de larvas do primeiro ínstar. O maior acúmulo de silício foliar no feijoeiro foi observado para a dose de $111.1 \mathrm{~kg} \mathrm{ha}^{-1}$ de silício. A sobrevivência larval de $S$. frugiperda não foi afetada pela adubação de plantas de feijoeiro com silício. Porém, o período de desenvolvimento larval aumentou à medida que houve o aumento das doses de silício. A não preferência das lagartas de $S$. frugiperda aumentou proporcionalmente às doses de silício testadas. A adubação com silicato de potássio obteve sucesso no controle de S. frugiperda nas dosagens de 100 e $200 \mathrm{~kg} \mathrm{ha}^{-1}$, pois mesmo não sendo uma cultura acumuladora de silício, obteve uma resposta satisfatória à adubação, diminuindo a preferência alimentar das lagartas e aumentando seu período de desenvolvimento larval.

Palavras-chave: Manejo integrado de pragas, resistência de plantas a insetos, Phaseolus vulgaris L.

\section{Silicon doses, through soil, in the induction of resistance to Spodoptera frugiperda in the bean plant}

\begin{abstract}
This study aimed to verify the effects of different doses of silicon in bean induction of resistance to S. frugiperda. It was adopted a completely randomized design with four treatments and five repetitions. The treatments were represented by silicon levels: $0 \mathrm{~kg} \mathrm{ha}^{-1} ; 50 \mathrm{~kg} \mathrm{ha}^{-1} ; 100 \mathrm{~kg} \mathrm{ha}^{-1}$ and $200 \mathrm{~kg} \mathrm{ha}^{-1}$. The potassium silicate was applied to the soil with the planting fertilization. The parameters evaluated were: survival of larvae after 48 hours, the larval survival, biomass of larvae at 14 days of age, larval development period, biomass pupae viability of larval and pupal stages and feeding non-preference of the first instar larvae. The greatest accumulation of foliar silicon in bean $(01.04 \%)$ was observed for the dose of $111.1 \mathrm{~kg} \mathrm{ha}^{-1}$ silicon. It follows that larval survival not affected by fertilizer bean plants with silicon $(\mathrm{p}=0.7045)$. However, the larval development period was increased as the increase of silicon doses. The non-preference of S. frugiperda larvae increased proportionally to the silicon doses. A fertilizer with potassium silicate succeeded in control of $S$. frugiperda in dosages of 100 and $200 \mathrm{~kg} \mathrm{ha}^{-1}$, for even it not being an accumulator culture of silicon, it obtained a satisfactory response to fertilization, decreasing the preference of caterpillars and increasing their larval development period.
\end{abstract}

Keywords: Integrated pest management, insect-resistant plants, Phaseolus vulgaris L. 


\section{Introdução}

O cultivo do feijoeiro no Brasil é feito em três épocas (das águas, da seca e de inverno), sendo frequentemente observada baixa produtividade, principalmente nas épocas tradicionais de cultivo (águas e seca). Essa baixa produtividade pode estar associada à ocorrência de pragas e doenças.

Dentre as pragas que ocorrem na cultura, merece destaque a Spodoptera frugiperda, uma espécie polífaga que ataca distintas culturas economicamente importantes em diversos países. A ocorrência desta praga na cultura do feijão foi tema do estudo realizado por Borges et al. (2012), que comparou o período larval em diversas culturas, relatando que a lagarta de $S$. frugiperda desenvolve-se bem na cultura do feijão, apresentando adaptação intermediária quando comparada com a cultura do sorgo.

O controle de $S$. frugiperda tem sido realizado com o uso de inseticidas químicos, que são aplicados logo que detectada sua ocorrência na cultura (Castro et al., 2009). No entanto, a utilização de produtos sintéticos geralmente possui custo elevado, com altos riscos de toxicidade e contaminação ambiental, podendo causar desequilíbrio biológico.

Na busca de alternativas ao uso destes produtos, têm sido estudadas outras formas de controle, como a utilização de inseticidas botânicos, controle biológico, cultivo de variedades resistentes e até mesmo a associação destes métodos de controle.

Estudos têm mostrado que o silício pode estimular o crescimento e a produção vegetal por meio de várias ações indiretas, causando aumento no teor de clorofila nos tecidos das folhas, o que as torna mais eretas, atrasando a senescência, aumentando a rigidez estrutural dos tecidos e propiciando proteção contra fatores abióticos e bióticos, como a incidência de insetos-praga (Epstein e Bloom, 2006; Ma e Yamaji, 2008).

Fertilizantes à base de silício são citados na literatura como indutores de resistência (Datnoff et al., 2001), sendo essa indução uma estratégia potencial nos programas de Manejo Integrado de Pragas (Costa e Moraes, 2002). Em sorgo, Costa e Moraes (2002) verificaram que a aplicação de silicato de cálcio induziu resistência ao pulgão verde Schizaphis graminum.

$\mathrm{O}$ aumento da resistência das plantas aos herbívoros pode ser causado pela redução da digestibilidade e/ou aumento da dureza dos tecidos das plantas, devido à deposição da sílica amorfa nas células da epiderme. Além disto, o silício solúvel está envolvido na defesa química induzida por meio do aumento da produção de enzimas de defesa ou da possível melhoria na liberação de voláteis responsáveis pela atração de inimigos naturais, favorecendo assim o controle biológico de insetos-praga (Reynolds et al., 2009).
Goussain et al. (2002) observaram maior mortalidade e aumento de canibalismo em grupos de lagartas de $S$. frugiperda quando estas foram alimentadas com folhas de plantas de milho tratadas com silício. Foi sugerido que a aplicação de silício pode dificultar a alimentação de lagartas, causando aumento de mortalidade e de canibalismo, tornando, portanto, as plantas de milho mais resistentes a essa praga.

Diante do exposto, o objetivo do presente trabalho foi avaliar os efeitos de diferentes doses de silício aplicadas via solo, na resistência do feijoeiro a Spodoptera frugiperda.

\section{Material e Métodos}

Inicialmente, estabeleceu-se uma criação de Spodoptera frugiperda para a obtenção das lagartas utilizadas para a realização dos testes.

As lagartas foram mantidas em recipientes plásticos com tampa de 7,0 cm de diâmetro e 5,0 cm de altura, alimentadas com dieta artificial (Greene et al., 1976) até a fase de pupa. Nesta fase, procedeu-se à separação das pupas por sexo e ao acondicionamento em placas de Petri de $9,5 \mathrm{~cm}$ de diâmetro, até a emergência dos adultos.

Os adultos foram mantidos em gaiolas confeccionadas com tubos de PVC de $10 \mathrm{~cm}$ de diâmetro e $25 \mathrm{~cm}$ de altura, sendo fechadas em uma das extremidades com tecido voil e revestidas com folha branca lisa em seu interior. Cada gaiola continha 10 casais de $S$. frugiperda, emergidos no mesmo dia. Os adultos foram alimentados com solução de mel a $10 \%$, embebida em algodão e colocada dentro de um recipiente plástico. $\mathrm{O}$ alimento foi renovado diariamente, de modo a evitar sua contaminação e fermentação.

O papel e o tecido onde as massas de ovos foram ovipositados foram recortados e acondicionados em recipientes plásticos com dieta até a eclosão das lagartas.

\section{Obtenção de plantas utilizadas para a realização dos experimentos}

As folhas de feijão utilizadas nos estudos de biologia e não preferência para alimentação de $S$. frugiperda foram obtidas em vasos cultivados no viveiro de mudas do Instituto Federal do Triângulo Mineiro (IFTM), campus Uberlândia.

A semeadura foi realizada em vasos de polietileno com capacidade para 5 litros de solo, preenchidos com mistura de terra e composto orgânico na proporção de 3:1. Foram semeadas quatro sementes do cultivar Carioca por vaso. Dez dias após a emergência foi realizado o desbaste, mantendo-se duas plantas por 
vaso. As plantas foram irrigadas diariamente, de modo a suprir suas necessidades hídricas.

A fonte de Si utilizada para a adubação foi o silicato de potássio na forma líquida (Fertisilício), o qual apresenta $12 \%$ de Si total e $12 \%$ de $\mathrm{K}_{2} \mathrm{O}$, com densidade de $1,38 \mathrm{~g} \mathrm{~mL}^{-1}$.

$\mathrm{O}$ silicato de potássio foi diluído em água e adicionado ao solo logo após o plantio, em diferentes dosagens, que constituíram os tratamentos: tratamento 1: $0 \mathrm{~kg} \mathrm{ha}^{-1}$; tratamento 2: $50 \mathrm{~kg} \mathrm{ha}^{-1}$; tratamento 3: 100 $\mathrm{kg} \mathrm{ha}^{-1}$ e tratamento 4: $200 \mathrm{~kg} \mathrm{ha}^{-1}$.

\section{Aspectos biológicos de Spodoptera frugiperda}

$\mathrm{O}$ estudo dos aspectos biológicos de $S$. frugiperda foi conduzido no Laboratório de Entomologia da Universidade Federal de Uberlândia, Uberlândia-MG, em ambiente com temperatura média de $25 \pm 2^{\circ} \mathrm{C}$, UR $60 \pm 10 \%$ e fotofase de 12 horas.

Lagartas recém-eclodidas foram individualizadas em recipientes plásticos de $200 \mathrm{~mL}$ com papel filtro umedecido com água destilada, e alimentadas com seções de folhas coletadas das plantas cultivadas em vaso. As seções foram padronizadas em $4,0 \mathrm{~cm}^{2}$ e todas as lagartas receberam a mesma quantidade de alimento diariamente. Antes de serem oferecidas às lagartas, as folhas foram imersas em solução de hipoclorito de sódio a $1 \%$, por aproximadamente três minutos, sendo em seguida lavadas com água destilada. Posteriormente, as mesmas foram cortadas com auxílio de uma tesoura, de forma a serem acondicionadas nos recipientes e em quantidade suficiente para alimentação das lagartas. A limpeza e observação das placas foram realizadas diariamente, e o alimento trocado de acordo com a necessidade.

Avaliou-se durante o experimento o período de desenvolvimento (dias) e a biomassa de lagartas e pupas (g). Para avaliar o desenvolvimento larval, confinou-se uma larva recém-eclodida e sadia por copo plástico (200 $\mathrm{ml})$. Foram utilizadas 10 lagartas por tratamento, sendo que cada uma representou uma única repetição. A cada dois dias foi observado o desenvolvimento das lagartas e, aos 10 dias após a eclosão, realizou-se a pesagem das sobreviventes. Após 24 horas da formação das pupas, foi avaliada a biomassa por meio de balança analítica de precisão.

Não preferência para alimentação de lagartas de $S$. frugiperda em plantas de feijoeiro submetidas a diferentes doses de silício, em testes com chance de escolha

Para o teste de não preferência para alimentação de lagartas foram cortadas seções de folhas de feijão das plantas oriundas dos diferentes tratamentos, em uma dimensão de $4 \mathrm{~cm}^{2}$. Os pedaços de folhas foram então dispostos aleatória e circularmente em arenas. Cada arena foi formada por um recipiente plástico de $25 \mathrm{~cm}$ de diâmetro, revestido ao fundo com papel filtro umedecido com água destilada. Para o centro da arena foram transferidas 12 lagartas de $3^{\circ}$ instar, em seguida, os recipientes foram fechados.

Cada arena foi considerada uma repetição, sendo utilizadas quatro repetições no total. Em seguida, avaliou-se a atratividade das lagartas em relação aos diferentes cultivares nos períodos de 1, 3, 15, 30, 60, 720 e 1440 minutos após a liberação das mesmas.

\section{Análise foliar}

A determinação da quantidade de silício foliar foi realizada de acordo com a metodologia proposta por Korndörfer et al. (2004). Portanto, moeu-se o material vegetal em moinho tipo Willey, acondicionando-o em sacos plásticos. Então, pesou-se $0,1 \mathrm{~g}$ do material vegetal moído em tubos de polipropileno de $100 \mathrm{~mL}$.

O processo de extração de silício na planta é feito através da oxidação da matéria orgânica, isto é, eliminação do carbono do tecido vegetal com água oxigenada (digestão). O hidróxido de sódio adicionado à solução digestora tem a finalidade de melhorar a eficiência do oxidante $\left(\mathrm{H}_{2} \mathrm{O}_{2}\right)$ e aumentar o $\mathrm{pH}$ da solução, visando manter o silício do tecido vegetal em solução (Korndörfer et al., 2004).

\section{Delineamento estatístico}

O delineamento estatístico utilizado foi o inteiramente casualizado (DIC) com quatro tratamentos, sendo eles quatro doses de silicato de potássio: tratamento 1: $0 \mathrm{~kg} \mathrm{ha}^{-1}$; tratamento 2: $50 \mathrm{~kg} \mathrm{ha}^{-1}$; tratamento 3: $100 \mathrm{~kg} \mathrm{ha}^{-1}$ e tratamento 4: $200 \mathrm{~kg} \mathrm{ha}^{-1}$.

Quanto aos aspectos biológicos, foram utilizadas dez repetições, sendo cada uma representada por uma lagarta por copo plástico.

O teste de não preferência com chance de escolha foi realizado com quatro repetições, sendo cada uma composta por 12 lagartas.

O silício foliar foi analisado a partir de cinco repetições com as folhas de feijão retiradas de cada tratamento.

\section{Análise estatística}

Os dados foram submetidos à análise de variância simples e a comparação das médias feita pelo teste de Tukey a 5\% de probabilidade, pelo programa SISVAR (Versão 5.3), e análise de regressão para os resultados que deram diferença significativa $(\mathrm{p}<0,05)$.

\section{Resultados e Discussão}

De acordo com o modelo matemático utilizado, pode-se estimar que o maior acúmulo de silício foliar no feijoeiro (4.01\%) se dá na dose de $111.1 \mathrm{~kg} \mathrm{ha}^{-1}$ de silício (Figura 1). 


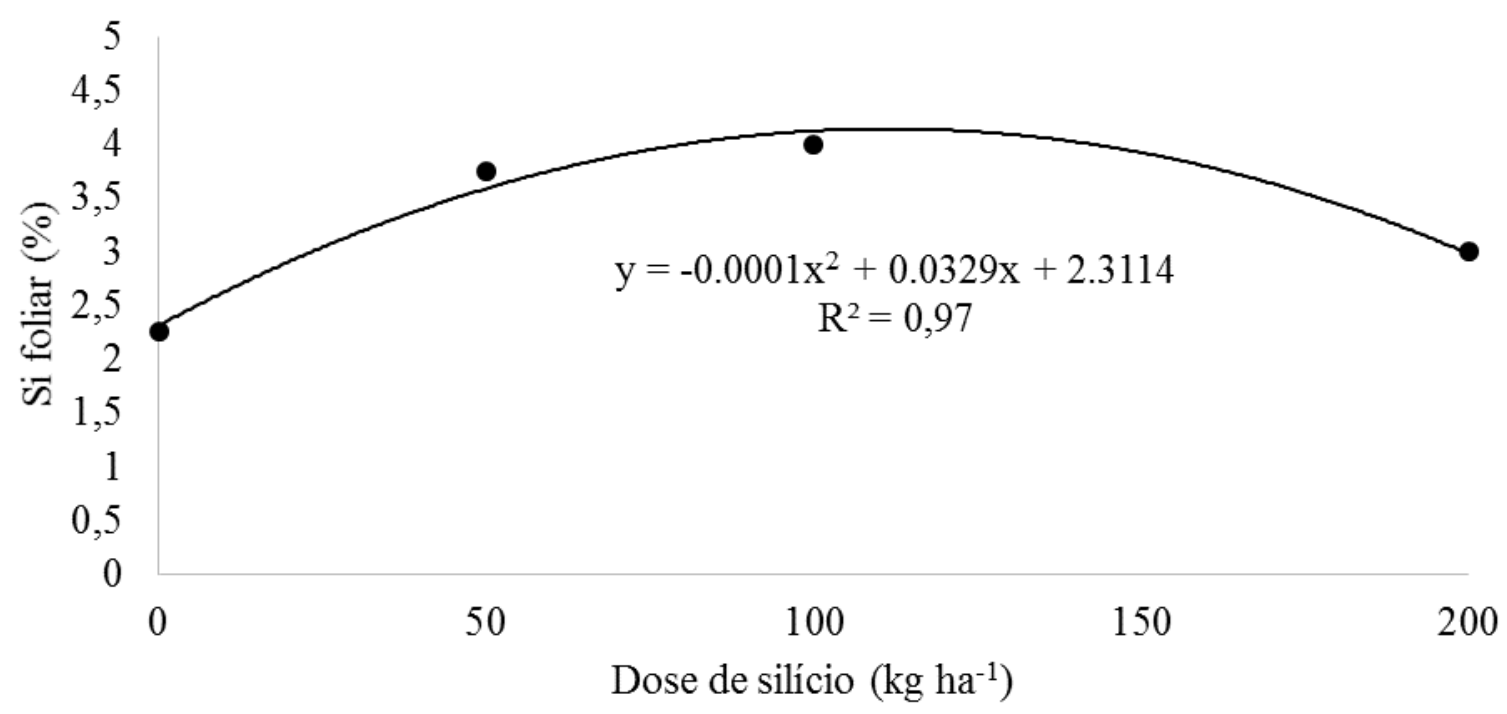

Figura 1- Teor de silício foliar em função das doses de silício aplicadas via solo. Uberlândia/MG 2015.

Mesmo não sendo uma planta acumuladora de silício (Ma e Yamaji, 2006), o feijão foi responsivo à adubação silicatada, atingindo a concentração de silício foliar igual a $4,01 \%$ ou $40,1 \mathrm{~g} \mathrm{~kg}^{-1}$. Essa concentração foi alta para o feijão, o que favoreceu os estudos sobre a influência do silício na biologia e comportamento de Spodoptera frugiperda. De acordo com Takahashi et al. (1990), as leguminosas como o feijão apresentam teor foliar de silício geralmente menor que $5 \mathrm{~g} \mathrm{~kg}^{-1}$. A alta concentração do silício foliar pode ter sido favorecida pelo tipo de fertilizante utilizado como fonte.

\section{Aspectos biológicos de Spodoptera frugiperda}

O período de desenvolvimento das lagartas de $S$. frugiperda $(\mathrm{p}=0.7045)$ e a biomassa de pupa $(\mathrm{p}=0.9017)$ não foram afetados pela adubação de plantas de feijoeiro com silício (Tabela 1).

No entanto, o período de desenvolvimento das lagartas foi influenciado pelo silício $(\mathrm{p}=0,0020)$ (Figura 2), ou seja, aumentou à medida que houve o aumento nos níveis de silício aplicados ao solo. Para cada $1 \mathrm{~kg} \mathrm{ha}^{-1}$ de silício adicionado ao solo, o período de desenvolvimento foi aumentado em $34 \mathrm{~min}$.

Tabela 1. Período de desenvolvimento das lagartas (dias), biomassa de larvas e pupas (g) de $S$. frugiperda alimentadas com plantas de feijoeiro em função das doses de silício.

\begin{tabular}{|c|c|c|c|}
\hline $\begin{array}{l}\text { Níveis de silício } \\
\left(\mathrm{kg} \mathrm{ha}^{-1}\right)\end{array}$ & Tempo de sobrevivência (dias) ${ }^{\text {n.s. }}$ & Biomassa de larva (g) ${ }^{\text {n.s. }}$ & Biomassa de pupa $(\mathrm{g})$ \\
\hline 0 & 4,90 & 0,19 & 0,31 \\
\hline 50 & 3,35 & 0,17 & 0,31 \\
\hline 100 & 3,62 & 0,16 & 0,31 \\
\hline 200 & 3,85 & 0,17 & 0,31 \\
\hline
\end{tabular}

${ }^{\text {n.S. }}$ Não significativo pelo teste $\mathrm{F}(\mathrm{p}>0,05)$.

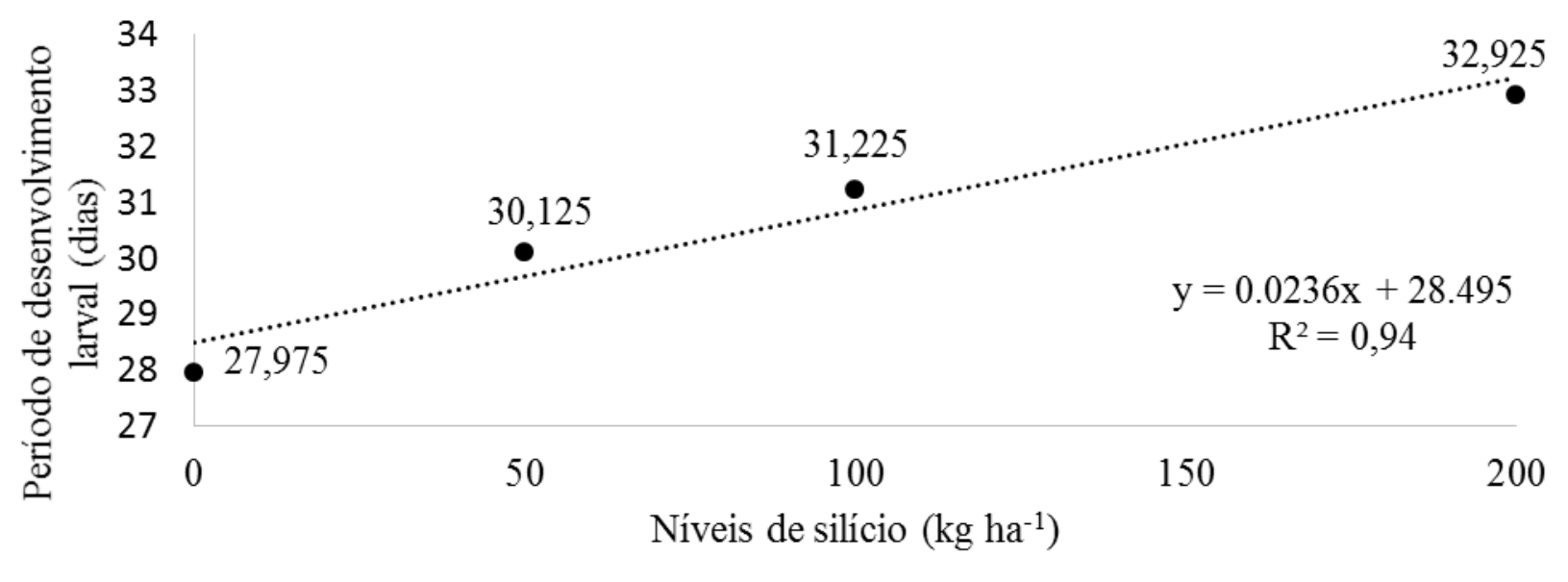

Figura 2- Período médio de desenvolvimento larval em função dos níveis de silício aplicados via solo. 
O aumento no ciclo de vida das lagartas, quando alimentadas com plantas submetidas a diferentes doses de silício, pode estar relacionado à dificuldade de alimentação das mesmas nas folhas tratadas, já que o aumento de sua concentração nas plantas contribui para o endurecimento da parede celular (Datnoff et al., 2001), para a redução da digestibilidade das folhas e, portanto, para a redução das taxas de crescimento das lagartas (Massey et al., 2007). Em cacaueiro, doses crescentes de $\mathrm{Si}$ aplicadas via foliar reduziram a preferência do pulgão Aphis aurantii (Pinto et al., 2012). Dias et al. (2014) também relataram a não preferência de Sitobion avenae (Fabricius, 1775) por plantas de trigo adubadas com silício, além da observação da indução de resistência por antibiose por esse nutriente. Provavelmente, os elevados níveis de silício nos tecidos foliares tornam os insetos incapazes de ingerir quantidades suficientes de nutrientes e água (Panda e Kush, 1995), acarretando alterações fisiológicas.

Não preferência para alimentação de lagartas de $S$. frugiperda em plantas de feijoeiro submetidas a diferentes doses de silício, em testes com chance de escolha

A não preferência não foi observada para os diferentes níveis de silício nos testes com chance de escolha aos 1, 3, 15 e 30 min de avaliação do número de lagartas no feijoeiro ( $\mathrm{p}=0.5748 ; \mathrm{p}=0.4228 ; \mathrm{p}=0.5748 ; \mathrm{p}=0.4891$, respectivamente $)$ (Tabela 2). Portanto, apenas 30 minutos de avaliação não é um tempo suficiente para que as lagartas façam a avaliação da planta hospedeira da qual se alimentarão. Porém, a não preferência foi observada aos 60, 720 e $1440 \mathrm{~min}$ de avaliação $(p=0,0138 ; p=0.0001 ; p=0.0011$, respectivamente) (Figuras 3, 4 e 5).

No teste com chance de escolha para as lagartas de $S$. frugiperda, avaliado aos $60 \mathrm{~min}$ (1h), aos $720 \mathrm{~min}$ (12h) e aos 1440 min (24h), foi observada uma redução do número de lagartas à medida que houve aumento da quantidade de silício utilizada para a nutrição do feijoeiro (Figuras 3, 4 e 5), ou seja, para cada $1 \mathrm{~kg} \mathrm{ha}^{-1}$ de silício adicionado ao solo, houve redução de 0,0119 lagartas aos $60 \mathrm{~min}$, de 0,0166 aos 720 min e de 0,0141 aos 1440 min após a liberação das mesmas. Essa redução pode ser explicada pela deposição de sílica amorfa nas folhas do feijoeiro, cujo solo recebeu as maiores quantidades de silício. Outra possível explicação para a não preferência das lagartas por plantas adubadas com maiores doses de silício é em relação à liberação de compostos voláteis não atrativos a elas.

Quando foi analisado o número de lagartas nas plantas que não receberam a adubação com silício, foi possível notar que o número de lagartas foi logaritmicamente maior a partir dos 60 min de condução do teste de escolha, ou 60 min após a liberação das lagartas para efetuarem a escolha $(\mathrm{p}=0.0008)$ (Figura 6). Entretanto, o número de lagartas não variou em função do tempo de avaliação para as doses de silício testadas $\left(50,100\right.$ e $200 \mathrm{~kg} \mathrm{ha}^{-1}$ de $\mathrm{Si}$; com $\mathrm{p}=0.5950$, $\mathrm{p}=0.2914$ e $\mathrm{p}=2225$, respectivamente).

Tabela 2 - Número de lagartas de $3^{\circ}$ instar de Spodoptera frugiperda atraídas em diferentes tempos (minutos) nos tratamentos, em testes com chance de escolha. Temperatura: $26 \pm 1{ }^{\circ}$ C; U.R.: $60 \pm 10 \%$; fotofase: 12 horas.

Dose de Si $\left(\mathrm{kg} \mathrm{ha}^{-1}\right)$

Número de lagartas atraídas

(tempo em minutos)

\begin{tabular}{llllllll} 
& $1^{\prime}$ & $3^{\prime}$ & $15^{\prime}$ & $30^{\prime}$ & $60^{\prime}$ & $720^{\prime}$ & $1440^{\prime}$ \\
\cline { 2 - 7 } 0 & $1,25 \mathrm{a}$ & $1,00 \mathrm{a}$ & $1,00 \mathrm{a}$ & $2,00 \mathrm{a}$ & $3,00 \mathrm{~b}$ & $3,50 \mathrm{~b}$ & $3,25 \mathrm{~b}$ \\
50 & $2,00 \mathrm{a}$ & $1,50 \mathrm{a}$ & $1,25 \mathrm{a}$ & $2,00 \mathrm{a}$ & $2,00 \mathrm{~b}$ & $2,50 \mathrm{~b}$ & $2,50 \mathrm{~b}$ \\
00 & $2,25 \mathrm{a}$ & $2,20 \mathrm{a}$ & $2,00 \mathrm{a}$ & $1,50 \mathrm{a}$ & $1,75 \mathrm{ab}$ & $0,75 \mathrm{ab}$ & $1,00 \mathrm{ab}$ \\
00 & $2,00 \mathrm{a}$ & $1,50 \mathrm{a}$ & $1,25 \mathrm{a}$ & $1,00 \mathrm{a}$ & $0,50 \mathrm{a}$ & $0,25 \mathrm{a}$ & $0,50 \mathrm{a}$
\end{tabular}

Médias seguidas da mesma letra na coluna não diferem estatisticamente entre si, pelo teste Tukey $(\mathrm{p}<0,05)$.

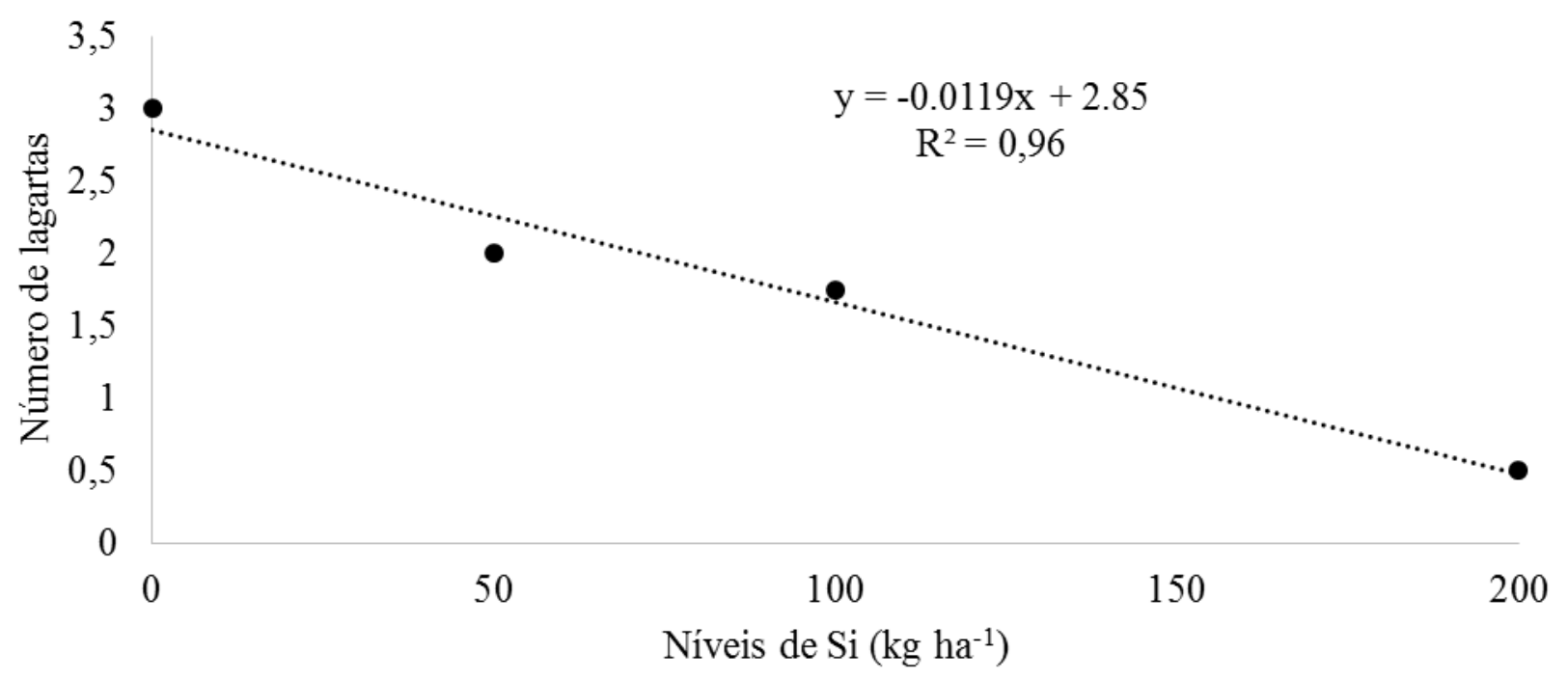

Figura 3- Número de lagartas em função das doses de silício aplicadas via solo, para preferência alimentar no período de 60 min (1h). 


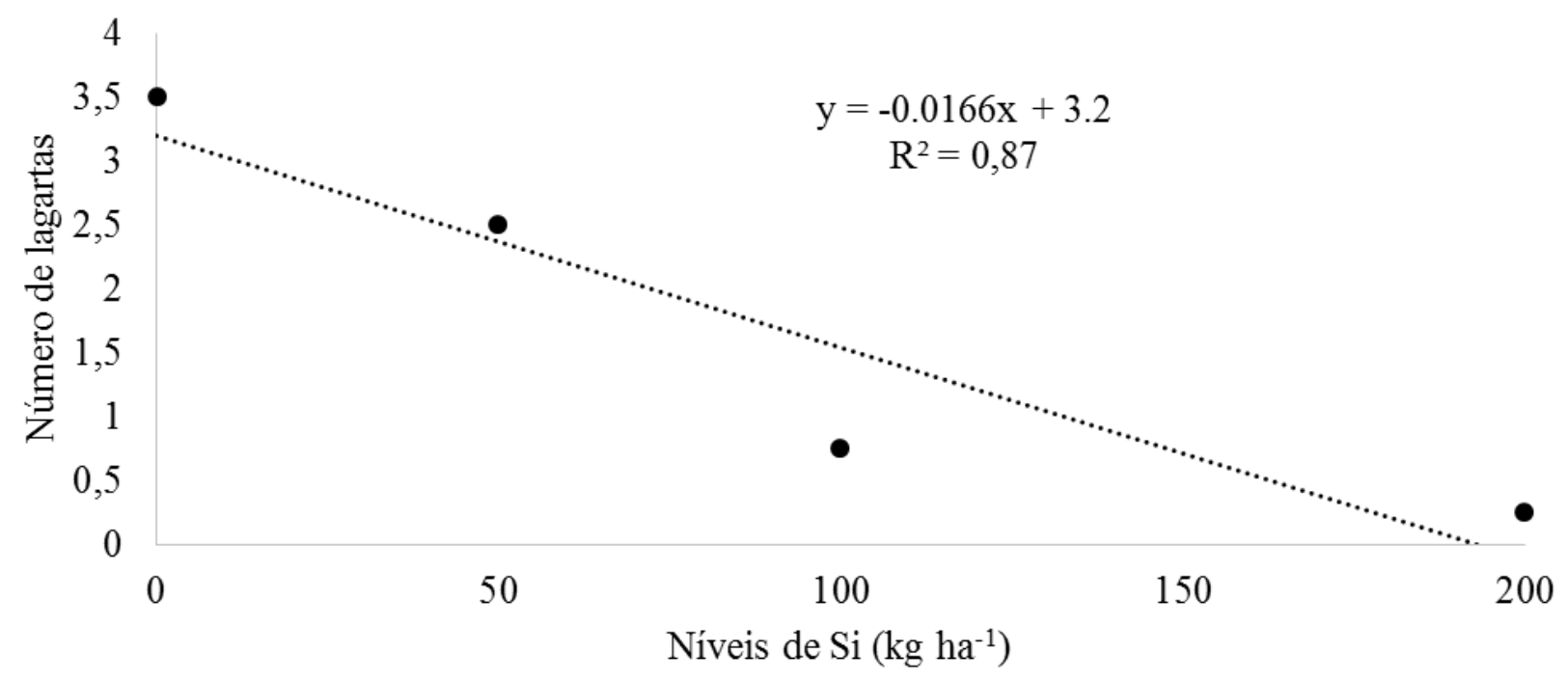

Figura 4- Número de lagartas em função das doses de silício aplicadas via solo, para preferência alimentar no período de 720 min.

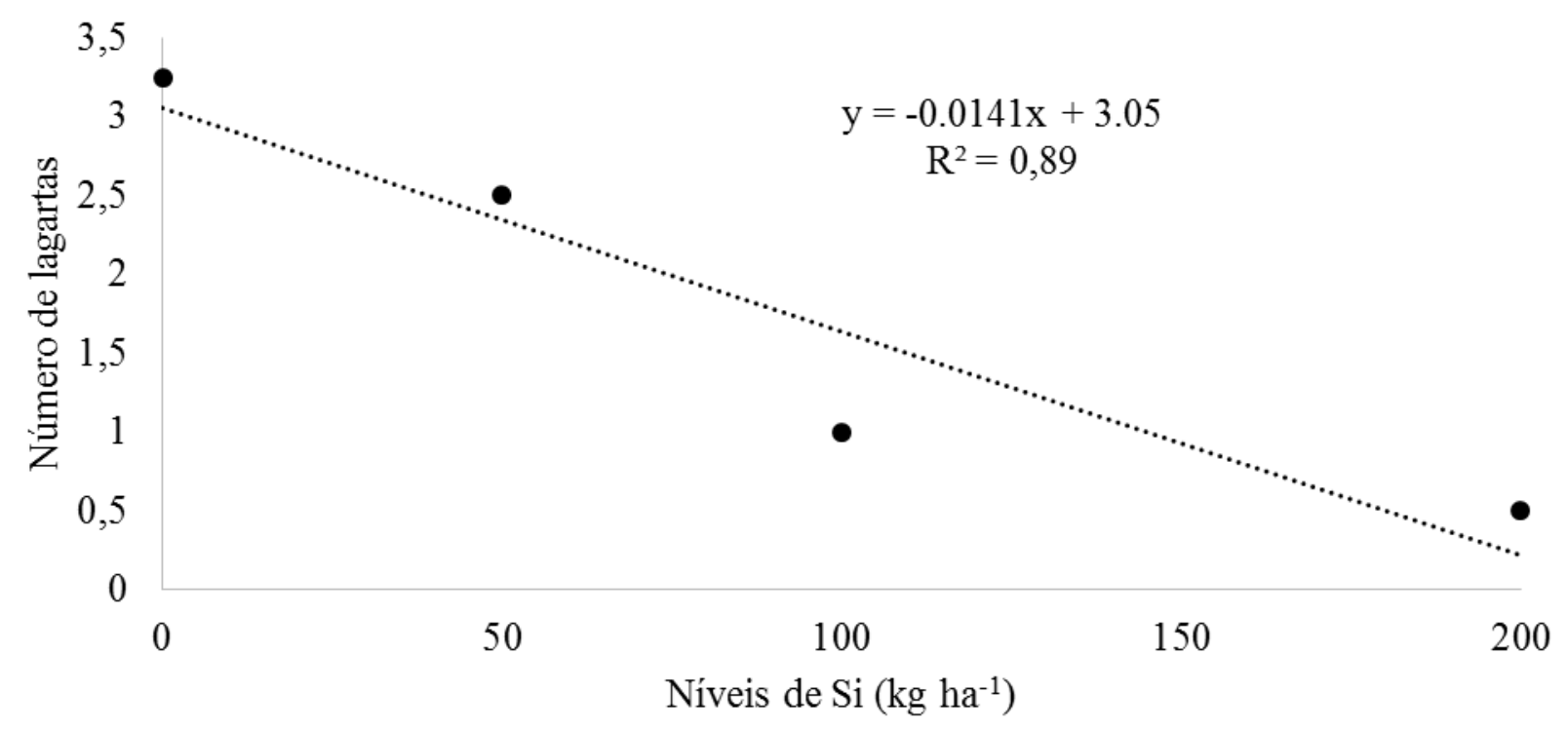

Figura 5- Número de lagartas em função das doses de silício aplicadas via solo, para preferência alimentar no período de 1440 min (24 h).

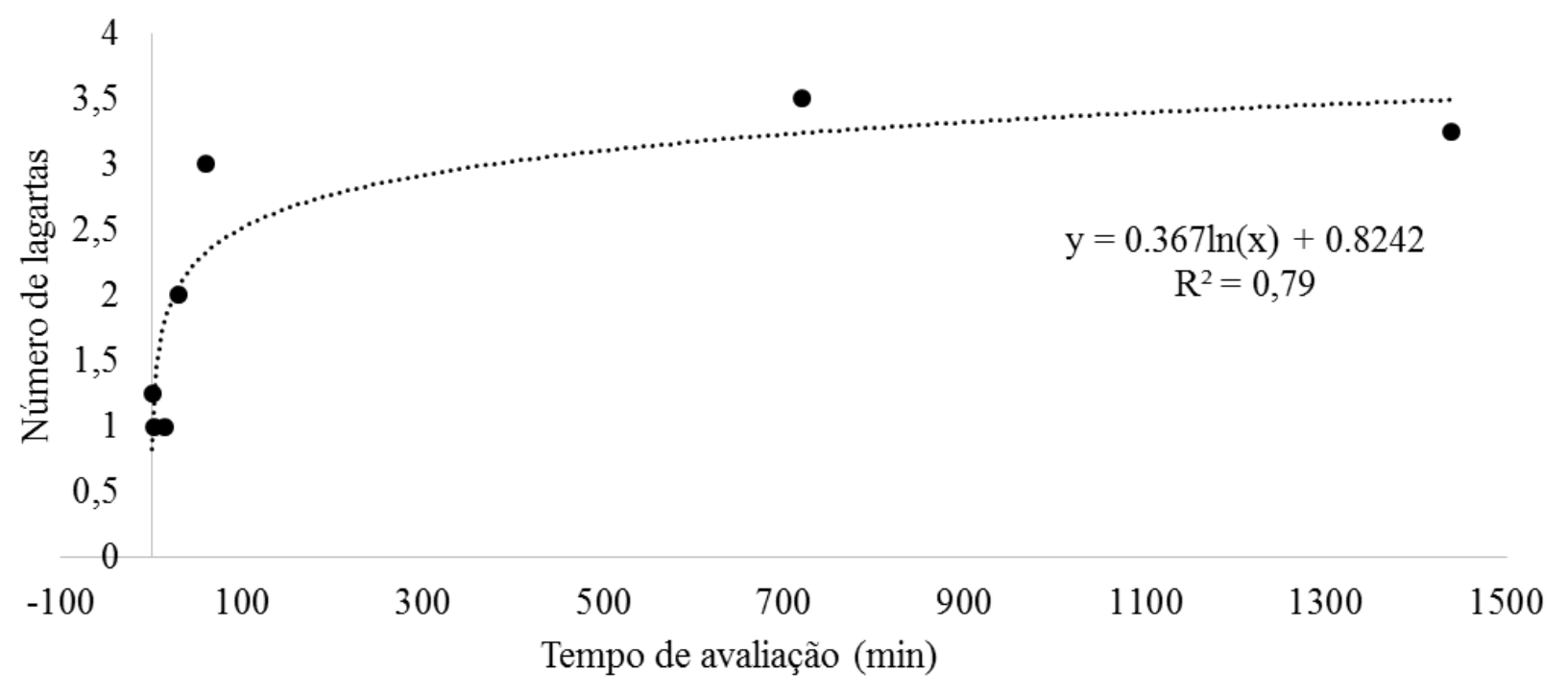

Figura 6- Número de lagartas em função do tempo na avaliação de preferência alimentar para testemunha $\left(0 \mathrm{~kg} \mathrm{ha}^{-1} \mathrm{de} \mathrm{Si}\right)$. 


\section{Conclusões}

A adubação com doses crescentes de silício (0 a 200 $\mathrm{kg} \mathrm{ha}^{-1}$ ) reduziu a preferência alimentar e aumentou o período de desenvolvimento das lagartas de Spodoptera frugiperda.

A aplicação do silício via solo favoreceu a resistência do feijoeiro à $S$. frugiperda através dos mecanismos de não preferência por alimentação e antibiose, podendo ser utilizada como estratégia no Manejo Integrado de Pragas nessa cultura.

\section{Referências Bibliográficas}

Borges, P. R. S., Saboya, R. de C. C., Saboya, L. M. F.; Santos, E. R. dos, Souza, S. E. A. de. 2012. Distribuição de massa seca e rendimento de feijão-caupi inoculadas com rizóbio em Gurupi, TO. Revista Caatinga, Mossoró, 25, 37-44.

Castro, E. M.; Pereira, F. J.; Paiva, R. 2009. Histologia Vegetal: Estrutura e Função de Órgãos Vegetativos. Lavras: UFLA.

Costa, R. R., Moraes, J. C. 2002. Resistência induzida em sorgo por silicato de sódio e infestação inicial pelo pulgão verde Schyzaphis graminum. Revista Ecossistema, Espírito Santo do Pinhal, 27, 37-39.

Datnoff, L. E., Snyder, G. H, Korndorfer, G. H. 2001. Silicon on agriculture. Amsterdam: Elsevier Science.

Dias, P. A. S., Sampaio, M. V., Rodrigues, M. P., Korndörfer, A. P., Oliveira, R. S., Ferreira, S. E., Korndörfer, G. H. 2014. Induction of resistance by silicon in wheat plants to alate and apterous morphs of Sitobion avenae (Hemiptera: Aphididae). Environmental Entomolgy, Oxford, 43, 4, 949-956.

Epstein, E., Bloom, A. 2006. Nutrição mineral de plantas: Princípios e perspectivas. Planta, Londrina. 403p.
Goussain, M. M., Moraes, J. C., Carvalho, J. G., Nogueira, N. L., Rossi, M. L. Efeito da aplicação de silício em plantas de milho no desenvolvimento biológico da lagarta-do-cartucho Spodoptera frugiperda (J. E. Smith) (Lepidoptera: Noctuidae). 2002. Neotropical Entomology, 31, n. 2, 305-310.

Greene, G. L., Leppla, N. C., Dickerson, W. A. 1976. Velvetbean catterpillar: a rearing procedure and artificial medium. Journal of Economic Entomology, 69, 487-488.

Korndörfer, G. H., Pereira, H. S., Camargo, M. S. 2004. Silicatos de cálcio e magnésio na agricultura. 2004. GPSiICIAG-UFU. 3. ed., 23 p. (Boletim Técnico 01).

Ma, J. F. \& Yamaji, N. Silicon uptake and accumulation in higher plants. 2006. Trends in Plant Science, Oxford, 11, n. 8, 392-397.

Ma, J. F. \& Yamaji, N. Functions and transport of silicon in plants. 2008. Celular and Molecular Life Science, Basel, 65, 3049-3057.

Massey, F. P.; Ennos, A. R.; Hartley, S. E. 2007. Grasses and the resource availability hypothesis: the importance of silicabased defences. Journal of Ecology, 95, 414 - 424.

Panda, N; Kush, G. S. 1995. Host plant resistance to insects. $\mathrm{CAB}$ International, Wallingdorf, Oxon.

Pinto, D. G., Aguilar, M. A. G., Souza, C. A. S., Silva, D. M., Siqueira, P. R., Cao, J. R., Zanetti, L. V. 2012. Alterações fisiológicas após aplicação de silício em cacau e sua influência na preferência por pulgões. Revista Ceres, 59, n.3, 360-367.

Reynolds R. L, Belnap J, Reheis M, Lamothe P, Luiszer F. 2009. Aeolian dust in Colorado Plateau soils: Nutrient inputs and recent change in source. Proceeding of National Academy of Science, 98, 7123-7127.

Takahashi, E., Ma, J. F., Miyake, Y. The possibility of silicon as a essential element for higher plants. 1990. Comments on Agricultural and Food Chemistry, London, 2, 99-122. 